that in the regions we have studied the direct effect of the moderate warming predicted in the next 50 years would be to reduce, at least briefly, both winter mortality and total mortality. This could be continued into a large, sustained reduction in overall mortality if additional action is taken to prevent relaxation of protective measures against outdoor and indoor cold stress as winters become milder. These findings should not, of course, diminish concerns about possible indirect effects of prolonged global warming, such as flooding of low lying areas due to a rise in sea level or about direct effects of heat stress in hotter regions.

Contributors: WRK and GCD designed the study; WRK is guarantor and drafted the paper, and GCD computed the data. All authors assembled data and contributed to their interpretation and to drafting and revision of the paper.

Funding: European Union grant BMH1-CT93-1229.

Competing interests: None declared.

1 Keatinge WR, Donaldson GC, Bucher K, Cordioli E, Dardanoni L, Jendritzky G, et al. Cold exposure and winter mortality from ischaemic heart disease, cerebrovascular disease, respiratory disease, and all causes in warm and cold regions of Europe. Lancet 1997;349:1341-6.

2 Keatinge WR, Coleshaw SRK, Easton JC, Cotter F, Mattock MB, Chelliah R. Increased platelet and red cell counts, blood viscosity and plasma cholesterol level during heat stress, and mortality from coronary and cerebral thromboses. Am J Med 1986;81:795-800.
Falcao JM, Valente P. Cerebrovascular diseases in Portugal: some epidemiological aspects. Acta Med Port 1977;10:537-42

Katsouyanni K, Trichopoulos D, Zabitsanos X, Touloumi G. The 1987 Athens heatwave. Lancet 1988;ii:575.

5 Kunst AE, Looman CW, Mackenbach JP. Outdoor air temperature and mortality in the Netherlands. Am J Epidemiol 1993;137:331-41.

6 Sartor F, Snacken R, Demuth C, Walckiers D. Temperature, ambient ozone levels, and mortality during summer 1994 heatwave in Belgium. Environ Res 1995;70:105-13.

7 Semenza JC, Rubin CH, Falter KH, Selanikio JD, Flanders WD, Howe H, et al. Heat-related deaths during the July 1995 heatwave in Chicago. N Engl J Med 1996;335:84-90.

8 Kalkstein LS, Greene JS. An evaluation of climate/mortality relationships in large US cities and the possible impacts of a climate change. Environ Health Perspect 1997;105:84-93.

9 Donaldson GC, Keatinge WR. Early increases in ischaemic heart disease mortality dissociated from, and later changes associated with, respiratory mortality after cold weather in south east England.J Epidemiol Communit Health 1997;51:43-8.

10 Martens WJM. Climate change, thermal stress and mortality changes. Soc Sci Med 1998;46:331-44.

11 Rooney C, McMichael AJ, Kovats, RS, Coleman MP. Excess mortality in Greater London during the1995 heatwave. J Epidemiol Community Health 1988;52:482-6.

12 Conn JW, Johnston MW, Louis LH. Acclimatization to humid heat (a function of adrenal cortical activity).J Clin Invest 1946;25:912-3.

13 Macfarlane A, Waller RE. Short term increases in mortality during heatwaves. Nature 1976;264:434-6.

14 Kalkstein LS. Health and climate change. Direct impacts in cities. Lancet 1993;264:1397-9.

15 Hulme M, Jenkins GJ. Climate change scenarios for the UK: scientific report. Norwich: Climatic Research Unit, 1998:1-88 (CIP technical report No 1.)

16 Mackenbach JP, Borst V, Schols JM. Heat-related mortality among nursing-home patients. Lancet 1997;349:1297-8.

(Accepted 25 April 2000)

\title{
Accuracy of the advanced trauma life support guidelines for predicting systolic blood pressure using carotid, femoral, and radial pulses: observational study
}

\author{
Charles D Deakin, J Lorraine Low
}

The advanced trauma life support course teaches that if only the patient's carotid pulse is palpable, the systolic blood pressure is $60-70 \mathrm{~mm} \mathrm{Hg}$; if carotid and femoral pulses are palpable, the systolic blood pressure is $70-80 \mathrm{~mm} \mathrm{Hg}$; and if the radial pulse is also palpable, the systolic blood pressure is more than $80 \mathrm{~mm} \mathrm{Hg} .{ }^{1}$ The only study to examine the accuracy of this model used non-invasive blood pressure measurements, which have a tendency to underestimate systemic arterial blood pressure during hypotension. ${ }^{2}$ No reliable data are therefore available to support the advanced trauma life support guidelines on which clinical decisions are made. We assessed whether the guidelines accurately predict systolic blood pressure by palpation of radial, femoral, and carotid pulses in hypovolaemic patients in whom blood pressure was measured using invasive arterial monitoring.

\section{Methods and results}

After obtaining approval of the study by the ethics committee, we studied sequential patients with hypotension secondary to hypovolaemic shock and in whom invasive arterial blood pressure monitoring had been established. An observer blinded to the blood pressure palpated the radial, femoral, and carotid pulses, and the invasive systolic blood pressure was recorded.

The 20 sequential patients studied over the three year period were aged 18-79 years. Not all pulses were

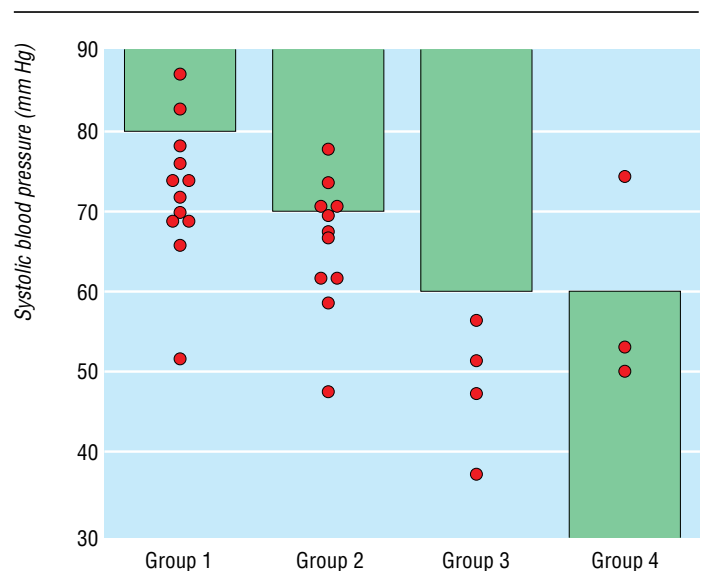

Dot plot showing the distribution of systolic blood pressure according to palpable pulses (group 1: radial, femoral, and carotid pulses present; group 2: femoral and carotid pulses only; group 3: carotid pulse only; group 4: radial, femoral, and carotid pulses absent); shaded areas indicate blood pressures expected according to advanced trauma life support guidelines
Shackleton Department of Anaesthetics, Southampton General Hospital NHS Trust, Southampton SO16 6YD

Charles D Deakin consultant anaesthetist continued over BMJ 2000;321:673-4 bmj.com

This article is part of the BMJ's randomised controlled trial of open peer review. Documentation relating to the editorial decision making process is available on the BMJ's website 
Health Care Research Unit Southampton General Hospital NHS Trust, Southampton SO16 6YD

J Lorraine Low medical statistician Correspondence to: C D Deakin cddeakin@ hotmail.com palpable when a reading was taken because a sterile operating field impaired access to the patients. The radial pulse always disappeared before the femoral pulse, which always disappeared before the carotid pulse. The data were split into four subgroups: radial, femoral, and carotid pulses present (group 1), femoral and carotid pulses only (group 2), carotid pulse only (group 3), and radial, femoral, and carotid pulses absent (group 4).

The figure shows the distribution of the systolic blood pressure in each of these groups. The reference lines in the figure at $80 \mathrm{~mm} \mathrm{Hg}, 70 \mathrm{~mm} \mathrm{Hg}$, and $60 \mathrm{~mm}$ $\mathrm{Hg}$ represent the values that, according to the advanced trauma life support guidelines, the systolic blood pressure is expected to exceed for groups 1,2 , and 3 respectively.

In group 1, 10/12 (83\%) subjects had a systolic blood pressure $<80 \mathrm{~mm} \mathrm{Hg}$ (mean $72.5 \mathrm{~mm} \mathrm{Hg}$ (reference range 55.3-89.7 $\mathrm{mm} \mathrm{Hg}$ )). In group 2, $10 / 12(83 \%)$ subjects had a systolic blood pressure $<70 \mathrm{~mm} \mathrm{Hg}$ (mean $66.4 \mathrm{~mm} \mathrm{Hg}(50.9-81.9 \mathrm{~mm} \mathrm{Hg})$ ). In group 3, none of the four patients had a systolic blood pressure $>60 \mathrm{~mm} \mathrm{Hg}$ as predicted by the advanced trauma life support guidelines. And in group 4, 2/3 patients had a systolic blood pressure $<60 \mathrm{~mm}$ $\mathrm{Hg}$ as predicted by the advanced trauma life support guidelines.

\section{Comment}

The advanced trauma life support guidelines for assessing systolic blood pressure are inaccurate and generally overestimate the patient's systolic blood pressure and therefore underestimate the degree of hypovolaemia. The minimum blood pressure predicted by the guidelines was exceeded in only four of 20 patients. The mean blood pressure and reference range obtained for each group indicate that the guidelines overestimate the systolic blood pressure associated with the number of pulses present. This study therefore does not support the teaching of the advanced trauma life support course on the relation between palpable pulses and systolic blood pressure.

Contributors: Data collection was carried out by CDD. JLL did the statistical analysis. CDD and JLL both wrote the report. CDD is the guarantor.

Funding: None.

Competing interests: None declared.

1 Collicott PE. Advanced trauma life support course for physicians. Chicago: American College of Surgeons, 1985.

2 Poulton TJ. ATLS paradigm fails. Ann Emerg Med 1988;17:107.

(Accepted 5 April 2000)

\section{Population based, prospective study of the care of women with epilepsy in pregnancy}

Susan D Fairgrieve, Margaret Jackson, Patricia Jonas, David Walshaw, Kathleen White, Tara L Montgomery, John Burn, Sally A Lynch

This prospective, population based study in the former Northern health region was designed to establish the proportion of pregnant women with a history of epilepsy; doctors supervising their care; effectiveness of preconceptional counselling and control of epilepsy; and use of medication and pregnancy outcomes.

\section{Subjects, methods, and results}

The project had approval from regional ethics committees. Pregnant women with epilepsy were recruited to the study, predominantly by community midwives. Women who consented were interviewed by using a standard questionnaire. Hospital notes were reviewed after the women had given birth. General practice and hospital notes were checked in one area to confirm the women's response regarding preconceptional advice. Between 1 January 1997 and 31 December 1998, 400 notifications of pregnancies to women with epilepsy were received (the total number of livebirths, stillbirths, and medical terminations for this period was 65478 , giving a proportion of all pregnancies to women with epilepsy of $6.1 / 1000)$.

Three hundred women were interviewed, $60 \mathrm{did}$ not consent to interview, contact was unsuccessful for 36, and 4 were notified retrospectively. Epilepsy management was undertaken by general practitioners in $182 / 300(61 \%)$ women; $214 / 300(71 \%)$ reported ongoing seizures; and 53/252 (21\%) women taking antiepileptic drugs reported no seizures for $>2$ years. A history of epilepsy was reported by 48 women who no longer took antiepileptic drugs. Of the remaining 252, $210(83.3 \%)$ were on monotherapy, most often carbamazepine (52\%) and sodium valproate $(35 \%)$. The diagnosis of epilepsy was questionable in 16/300 (5\%) women. Incomplete compliance with medication was reported by $157 / 252$ $(62.3 \%)$ women.

Only 113/300 (38\%) women recalled receiving preconceptional counselling. However, review of the notes of 25 women who denied having received advice showed that $8(32 \%)$ had been counselled. Less than $50 \%(88 / 199)$ planned their pregnancies and 27/111 reported oral contraceptive failure. Only 32 (11\%) took folate appropriately.

Of the 359/400 known pregnancy outcomes there were 330 live births (three sets of twins); two medical terminations, two stillbirths, 22 miscarriages, and five terminations.

The obstetric complication rate and mode of delivery were similar to that of the background population 